\title{
Gene alterations in head and neck carcinomas and their role in promoting malignant behavior (Review)
}

\author{
TIBOR GÖRÖGH ${ }^{1}$ and ULF HENNING BEIER ${ }^{2,3}$
}

\begin{abstract}
${ }^{1}$ Division of Experimental Oncology, Department of Otorhinolaryngology, Head and Neck Surgery, University of Schleswig Holstein, Campus Kiel, Arnold-Heller-Str. 14, D-24105 Kiel, Germany; ${ }^{2}$ Department of Pathology and Laboratory Medicine, and ${ }^{3}$ Division of Nephrology, Department of Pediatrics, The Children's Hospital of Philadelphia and University of Pennsylvania, 34th Street and Civic Center Boulevard, Philadelphia, PA 19104-4399, USA
\end{abstract}

Received November 17, 2009; Accepted December 14, 2009

DOI: 10.3892/ijo_00000526

\begin{abstract}
Head and neck squamous cell carcinoma (HNSCC) survival remains poor despite continuing efforts toward prevention, early detection, and improved treatment modalities. In part, this is thought to be due to a relative lack of molecular targeted therapeutic strategies beyond general mitosis inhibition, which sets a limit to what modern head and neck surgery can accomplish for advanced disease. The past 30 years have produced a large quantity of data, leading to a better understanding of HNSCC carcinogenesis and novel therapeutic agents, such as epidermal growth factor receptor blockers. This article reviews literature on the current understanding of molecular HNSCC carcinogenesis, and highlights the most promising therapeutic approaches.
\end{abstract}

\section{Contents}

1. Introduction

2. Oncogenes and tumor suppressor genes

3. Self-stimulation via growth signals

4. Tissue invasion and metastasis

5. Limitless self-replicative potential

6. Evading apoptosis

7. Angiogenesis

8. Escaping the immune response

9. Conclusion

\section{Introduction}

Squamous cell carcinoma of the head and neck is the sixth most common cancer worldwide. While potentially curable at

Correspondence to: Dr Tibor Görögh, Division of Experimental Oncology, Department of Otorhinolaryngology Head and Neck Surgery, University of Schleswig Holstein, Campus Kiel, ArnoldHeller-Str. 14, D-24105 Kiel, Germany

E-mail: gorogh@hno.uni-kiel.de

Key words: head and neck squamous cell carcinoma, carcinogenesis, tumor invasion, cancer therapy an early stage, more than $40 \%$ of patients present with locally advanced or metastatic disease at the time of diagnosis, with an overall 5-year survival rate between $40-63 \%$ (1). HNSCC mortality remains largely unimproved despite ongoing advancements in tumor surgery, as well as radio- and chemotherapy (2). A part of this problem is thought to be the relative lack of targeted radio- and chemotherapy regimens selected based upon tumor biological properties. The remarkable success of this type of targeted therapy has been demonstrated in BCR-ABL fusion protein blockade in chronic myeloid leukemia (3). It is understood that tumor prognosis heavily depends upon cancer cell biology. For example, HNSCC arising from human papilloma virus infections are associated with a relative survival advantage (4). Considerable research efforts have been dedicated to study the molecular biology of HNSCC. Over the last three decades, several cancer related transcripts have been suggested as factors of etiological importance. Some were recognized as biomarkers to guide treatment decisions, while others became targets for the development of 'intelligent drugs' (5). This article reviews molecular findings of HNSCC carcinogenesis and organizes them based upon the hallmarks of malignant tumors by Hanahan and Weinberg (6), as well as other important pathophysiological principles. Our aim is to discuss these findings in light of their significance for molecular disease mechanisms which are important for the development of novel therapeutic agents.

\section{Oncogenes and tumor suppressor genes}

Genetic anterations of oncogenes and tumor suppressor genes can affect their expression or may produce an altered gene product resulting in malignant transformation of the cell (reviewed in refs. 7-9). Altered expression of oncogenes has been considered as a prognostic factor in a variety of tumors. Particularly, upregulation of the myc genes has been reported to be prognostic indicators in different tumor entities. Kiaris et al showed that genetic instability of a repetitive element which is located within intron 1 of the $\mathrm{H}$-ras gene is associated with the nodal status of patients with HNSCC $(10,11)$. Spandidos et al found significant activation of multiple oncogenes (H-ras, K-ras, c-myc, fes, abl, sis) in premalignant and malignant head and neck solid tumors (12), and Field et al 
proposed that the enhanced expression of c-myc which was correlated with advanced stages of the disease, may be an effective prognostic indicator in head and neck cancer $(13,14)$.

In different neoplasias genetic alterations have mostly been studied to determine allelic imbalance or loss of heterozygosity to identify chromosome regions that may contain tumor suppressor genes. Field et al identified two regions in HNSCC that are most likely to be important in the development of head and neck carcinoma at 3p24-p25 and 3p13 and may indicate sites of novel tumor suppressor genes in this tumor entity (15). In a comprehensive study Field et al demonstrated a complex set of genetic alterations, in HNSCC where the highest loss of heterozygosity was found on the chromosome arms 3p, 9p, 17p and 18q (16). Similar observations were made by Nawroz et al (17) and Ah-See et al (18) indicating the importance of the analysis of accumulation of genetic aberration in head and neck tumors.

In a wide range of human cancer, an important factor controlling cellular growth is $\mathrm{p} 53$. The mechanisms responsible for loss of p53 in HNSCC can be divided into mutation of the p53 gene (about 50\%), inactivation by p53 modulators, or targeted degradation (as in the case of Human Papilloma Virus early E6 protein (19). Its loss of function is a characteristic early change frequently observed as a precursor to HNSCC (35), however, the p53 gene also have a role in the late stages of this disease (20). Field et al found, that mutations in the p53 gene at codon 249 are rare in HNSCC in contrast to hepatocellular carcinomas and their observations indicate that the hot spot mutations have occurred in the 238248 region $(20,21)$. Interestingly, p53 overexpression and mutations correlate with alcohol and tobacco abuse of patients with HNSCC $(22,23)$.

P53 can suppress carcinogenesis by several mechanisms. In response to a myriad of stress signals, p53 pathways can lead to two principal outcomes: repair of the acquired damage via initiation of a cell cycle arrest (G1/S) and resultant DNA repair, or self-destruction via apoptosis (24). For those types of cancer expressing wild-type p53 rendered non-functional by modulation or accelerated degradation, therapeutic options exist in utilizing the inherently functional p53 to a higher degree. This can be achieved by inhibiting the interaction of p53 with its central inhibitor, human double minute 2 (25). Another important part of growth inhibition is mediated via cell-cell contacts. In HNSSC such effects can be induced by adhesive glycoproteins facilitating cellular adhesion, attachment to extracellular matrix (ECM) and contact inhibition (26-28).

\section{Self-stimulation via growth signals}

Cellular growth factors are indispensible for mitosis. However, their signal cascade is also a chief pathway of malignant signal transduction. Alteration of extracellular growth signals, their cellular transmission, or intracellular circuits that translate those signals into action all can lead to malignant transformation (6). Stimulation of epidermal growth factor receptor (EGFR) and its associated pathways has long been suspected to undergo such alterations in the development of HNSCC (29). In 1997, Issing found that patients with simultaneous expression of transforming growth factor $\alpha$ (TGF- $\alpha)$ and its cell surface receptor EGFR had a poor prognosis. He hypothesized an autocrine loop, in which HNSCC cells synthesize their own growth factor (30). Grandis et al demonstrated a decrease in TGF- $\alpha$ production via antisense oligonucleotides which reduced cellular proliferation rate (31). EGFR itself has been described as inducible by carcinogenic growth factors leading to alteration of extracellular, as well as transcellular signal transduction (32). Subsequently, EGFR expression was investigated as a prognostic marker, and found to be associated with poor outcomes (33). EGFR has progressively become an important target of direct antineoplastic therapy, especially via the chimeric monoclonal EGFR antibody Cetuximab (34). In 2006, Bonner et al reported that the addition of Cetuximab to radiotherapy significantly prolonged locoregional control and decreased mortality compared to radiotherapy alone (35). Vermoken et al reported a phase III trial of Cetuximab as first-line treatment together with platinum and fluorouracil to treat patients with recurrent or metastatic HNSCC (36). As a result of these trials, Cetuximab has become an established component of HNSCC treatment.

Adverse effects of Cetuximab in HNSCC are still under investigation. From the colon cancer literature, known side effects of Cetuximab monotherapy are allergic reactions, acneiform rash, asthenia/malaise, fever, pulmonary and gastrointestinal symptoms (37). In addition, Cetuximab is described as causing hypomagnesemia due to inhibition of renal tubular reabsorption. However, this hypomagnesemia is posited to have antineoplastic effects (38). Giro et al recently observed a higher rate of radiation dermatitis in patients with HNSCC who were treated with Cetuximab and radiation therapy (39). It is conceivable that EGFR blockade impairs the regeneration of other tissues after surgery and radiochemotherapy. Continuous efforts to improve the side effect profile have been made, including research on other monoclonal antibodies against EGFR. Notably, the human monoclonal EGFR antibody Panitumumab has been studied and FDA approved for colorectal cancer (40). The principal advantage of Panitumumab is that it is a fully human monoclonal antibody, eliminating antibody formation against itself (41). At the same time, Cetuximab may elicit immune responses specifically for the mouse portion of the molecule leading to an immune reaction against the antibody and targeted tumoral cells (42). Panitumumab is currently being investigated in HNSCC patients as well.

Over time, compared to the high expectations that accompanied the introduction of anti EGFR therapy, results have been modest. Only $15 \%$ of the patients treated showed a clinical response, and these drugs contributed only to a relatively small overall survival benefit (42). One of the reasons for these results is a still incomplete understanding of the molecular mechanisms promoting HNSCC. The chief mechanism of action for both Cetuximab and Panitumumab is inactivation of EGFR activated signaling. That has important implications, as mutations in intracellular signaling molecules downstream of EGFR such as in the g-protein $\mathrm{K}$-ras can infer resistance to EGFR receptor blocker treatment (43).

EGFR-independent mechanisms, including soluble insulin growth factor 1 (IGF-1) and the intracellular nuclear factor-кB 
$(\mathrm{NF}-\kappa \mathrm{B})$, also contribute to the activation of key intracellular signaling routes in HNSCC growth $(44,45)$. Slominary et al proposed interrupting intracellular signaling of both the EGFR and IGF-1 systems, through targeted inhibition of the tyrosine kinases of both IGF-1R (NVP-AEW541) and EGFR (AG1478) (46). However, results so far exist only on a preclinical level.

\section{Tissue invasion and metastasis}

Local invasion and distant metastasis, rather than mere cell proliferation, are the key determinants of both morbidity and mortality for a vast majority of tumors. These two processes cause $90 \%$ of cancer related death (48). Mechanisms include dislodgement of HNSCC cells via loss of cell-to-cell contacts, secretion of enzymes facilitating dissolution of the basal lamina and other ECM structures, and tumor cell migration. In HNSCC, cellular dislodgement has been reported to be facilitated via loss of adhesion proteins, such as E-cadherin (49), claudin-7, connexin 31.1 (50), or FN (47). However, it also can occur secondary to expression of glycoproteins interfering with cellular adhesion, such as dysadherin (51).

ECM and basal lamina dissolution are in major part attributed to matrix metalloproteinases (MMP) being capable of cleaving ECM and basilar membrane macromolecules. In HNSCC high MMP expression was found to be associated with regional lymph node and distant metastases (52), and a higher rate of recurrence (53). Highly expressed MMP was also found in a variety of cancers, implicating their importance in tumor invasiveness and metastasis formation (54).

To this date, there is no clinical trial on MMP inhibitors in HNSCC published to the best of our knowledge. By analyzing the reasons for the relative lack of successful clinical trials despite promising pre-clinical data, Rosenthal and Matrisian suggested that mouse models used in preclinical studies with xenotransplanted tumor tissue may be inadequate, as these mice are immunodeficient. Additionally, their MMP genotype and phenotype is quite different from humans. MMP inhibitors may also fail as monotherapy, as they have little cytotoxic effects. Dosing was limited by musculoskeletal side effects, and thus it remains unclear whether other modalities of applying the medication could be beneficial (55).

ECM composition is regulated by a variety of factors other than MMP. The lysyl oxidase (LOX) enzymes are one of the prominent factors that have gained interest. LOX are secreted copper-dependent amine oxidases that catalyze the oxidation of peptidyl lysine to $\delta$-aminoadipic $\beta$-semialdehyde. This is an intermediate step in the formation of covalent crosslinkages between elastin and collagen, which is essential in the development and maintenance of the ECM (56). Consequentially, LOX were hypothesized to function as tumor suppressors by limiting cellular invasion. However, over time, the analysis of LOX family genes in cancer cell lines was found to be much more heterogeneous. Comprehensive investigations on gastric (57), colon (58), prostate (59), and breast cancer (60) indicated both decreased, as well as increased LOX gene expression. Interestingly, both LOX and lysyl-oxidase-like 4 (LOXL4) mRNA were found upregulated in HNSCC $(61,62)$. We found LOXL4 expression increased within the HNSCC and not the surrounding stroma cells $(62,63)$. This suggests a role in promoting tumor invasion and metastatis formation.

Further research on the LOX enzyme indicated other functional regions apart from its highly conserved copper and lysyl-tyrosyl-chinon (LTQ) binding domains necessary for the collagen/elastin linkage. These included regions promoting chemotactic responses, proliferation, and shifts between the normal and malignant phenotypes (64). This led to the hypothesis that intracellular and extracellular LOX may have entirely different functions. Erler et al showed a link between tissue hypoxia, the expression of LOX, and metastasis formation (65). In HNSCC, this correlation was confirmed in case of LOX expression as a poor prognostic marker $(63,66)$.

These findings have led to preclinical studies on therapeutic agents that might be utilized in cancer treatment. Notably, Bondareva et al investigated B-aminopropionitrile in mice that received breast cancer cells. They found that this agent could reduce the rate of new metastasis formation. However, the growth of existing metastases was not affected (67). In a feasibility study, we transfected cloned LOXL4mRNA into immature dendritic cells and showed that cellular expression of LOXL4 could provide an effective target for cell mediated immunotherapy (68). Another important aspect of metastasis formation is the phenomenon of directional movement, which is well characterized for many cells, particularly leukocytes. In 2004, Wang et al reported upregulation of chemokine receptor 7 on head and neck cancer cells as a novel mechanism of metastasis formation that could help 'home in' towards lymph nodes, and thus aid metastatic spread (69).

\section{Limitless self-replicative potential}

While the independence from external regulatory signals is a precondition for a cancer cell to develop replicative autonomy from its environment, this alone does not suffice to overcome other natural limitations of redundant mitosis, such as a terminal phase called crisis at the end of numerous replications (6). Wright et al observed that one in $10^{7}$ cells can spontaneously acquire the ability to overcome this natural limitation and form an 'immortalized cell' that has the ability to replicate itself endlessly (70).

In HNSCC, Mao et al showed that activation of telomerase, the enzyme responsible for elongating telomeres and thus enabling the cell to bypass the Hayflick limit, is frequent in HNSCC and may occur early in the neoplastic process (71). Thurnher et al suggested that elevated telomerase activity in HNSCC correlated with lymph node metastasis (72). While telomerase is a tempting target for cancer treatment, a number of anti-neoplastic agents and plant products were found to interfere with its function in hindsight $(73,74)$. There is evidence that telomerase activity is regulated by caspase activity, and that factors promoting apoptosis also reduce telomerase activity (75). New therapeutic attempts to decrease telomerase activity in HNSCC cells have been made via ceramide application (76).

\section{Evading apoptosis}

Tumor progression not only depends on cell replication and growth as delineated above, but also on cell survival, 
Table I. Targeted therapeutic agents in HNSCC.

\begin{tabular}{|c|c|c|}
\hline Therapeutic target & Compound & State of investigation in HNSCCa \\
\hline EGFR & Cetuximab & Established in HNSCC \\
\hline EGFR & Panitumumab & $\begin{array}{l}\text { Established in colon cancer, six phase II, and three } \\
\text { phase III trials in HNSCC }\end{array}$ \\
\hline IGF-1R tyrosine kinase & NVP-AEW541 & Preclinical \\
\hline EGFR tyrosine kinase & AG1478 & Preclinical \\
\hline $\mathrm{NF}-\kappa \mathrm{B}$ & Diferuloylmethane & $\begin{array}{l}\text { Preclinical in HNSCC, several phase III trials in other } \\
\text { cancers }\end{array}$ \\
\hline $\mathrm{NF}-\kappa \mathrm{B}$ & Curcumin & $\begin{array}{l}\text { Preclinical in HNSCC, several phase III trials in other } \\
\text { cancers }\end{array}$ \\
\hline MDM2-p53 interaction inhibitors & Nutlins & Preclinical \\
\hline MDM2-p53 interaction inhibitors & MI-219 & Preclinical \\
\hline MMP-2 & Marinastat & $\begin{array}{l}\text { Preclinical in HNSCC, three phase } 3 \text { trials in other } \\
\text { cancers }\end{array}$ \\
\hline MMP-2 & Prinomastat & Preclinical in HNSCC, two phase III, one phase II trial \\
\hline LOX & ß-aminopropionitrile & Preclinical \\
\hline Apoptosis induction, telomerase & Ceramide & $\begin{array}{l}\text { Preclinical in HNSCC, two phase II trials in other } \\
\text { cancers }\end{array}$ \\
\hline VEGF & Bevacizumab & $\begin{array}{l}\text { Established in glioblastoma multiforme, in HNSCC: } \\
\text { one phase III trial, } 16 \text { phase II trials and three } \\
\text { phase I trials }\end{array}$ \\
\hline VEGF & Aflibercept & One phase II trial, one phase III trial in other cancers \\
\hline VEGF receptor tyrosine kinase & Sorafenib & $\begin{array}{l}\text { Established in renal and liver cancer, in HSCC: } \\
\text { two phase I, one phase II trial }\end{array}$ \\
\hline
\end{tabular}

aState of investigation as reported on clinicaltrials.gov accessed October 2009, including active as well as completed or suspended trials.

maintaining a replication velocity greater than the cell rate of cell loss (6). In HNSCC, Yang et al showed that activation of the Wnt/ß-catenin signaling pathway promoted cell survival, by avoiding apoptosis, as well as invasive growth of HNSCC cells (77). Sniezek et al demonstrated $\delta N p 63 \alpha$ upregulated in tumors and underexpressed in the pro-apoptotic condition of lichen planus. This suggests an anti-differentiation and antiapoptotic role in the mucosal epithelium of the head and neck, possibly playing a pivotal role in the formation of HNSCC (78). We and Chiang et al reported that the proto-oncogene Pim-1, which functions to prevent premature onset of apoptosis, is upregulated in oral squamous cell cancer. This suggests an involvement into HNSCC carcinogenesis $(79,80)$. Pim- 1 acts as a MYC cofactor, phosphorylating the chromatin at MYC-target loci. This has been suggested to contribute to MYC-dependent transcriptional activation (81).

Another gene involved in evading apoptosis in HNSCC is the lysosomal enzyme galactocerebrosidase (GALC), responsible for the hydrolysis of numerous monohexidose glycosphingolipids. Glycosphingolipids are known to be increased on the surface of cancer cells and play an important role in inhibition of cellular adhesion and apoptosis (82). An increase in the concentration of glycosphingolipids on the cellular membrane of cancer cells leads to significant changes of the antigenic properties. These include the formation of tumor associated carbohydrate antigens, loss of adhesion, and increased cellular motility (82). Galactocerebroside inhibits the induction of apoptosis, whereas the product of its hydrolysis via GALC, ceramide, promotes it (83). We could show that GALC is repressed in HNSCC (84), which fits into a carcinogenesis model in which the metabolism of HNSCC cells is modified to inhibit apoptosis and promote loss of cell adhesion (85).

The role of ceramide as an enhancer of apoptosis has already found application in cancer research (86). Reynolds et al showed that ceramide has cytotoxic effects. Exposure of cells to radiation or chemotherapy is associated with increased ceramide levels due to enhanced de novo synthesis, catabolism of sphingomyelin, or both (87). Several approaches have been undertaken to increase the level of ceramide 


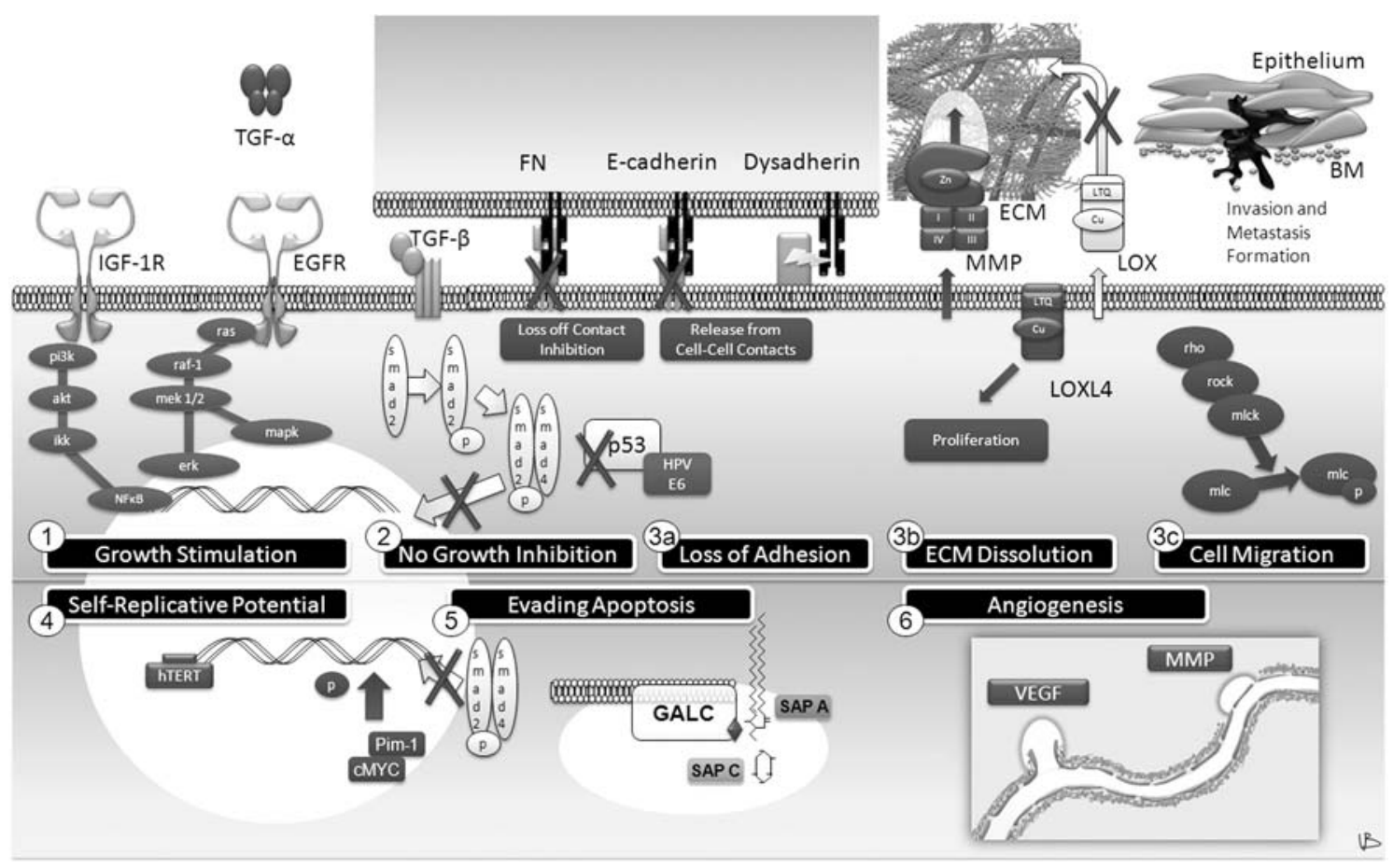

Figure 1. Molecular mechanisms promoting malignant behavior in HNSCC: growth stimulation (1) mediated via the epidermal growth factor receptor (EGFR) and insulin-like growth factor 1 receptor (IGF-1R) system. Resistance to growth inhibition (2) signals mediated by transforming growth factor (TGF) B, which also affects lysyl-oxidase (LOX) expression and apoptosis. Tumor invasion and metastasis formation (3) is mediated by loss of cell-cell and cell-ECM (extracellular matrix) contacts (3a), enzymatic disassembly of barrier ECM structures such as the basement membrane (BM), in which matrix metallo-proteinases (MMP) play an important role (3b), and cellular migration mediated by contractile filaments (3c). Immortalization of the cell (4) and evasion of apoptosis (5) are closely linked. Galactocerebrosidase (GALC) facilitates the separation of galactose and ceramide, and thus may help in promoting apoptosis. Pim1 is an activated oncogene involved in the suppression of MYC-induced apoptosis by interacting with MYC and mediating the phosphorylation of histone H3. Angiogenesis (6) in two different steps, disassembly of the existing vascular basement membrane [by MMP, see (3)], and, migration and growth along the provisional vascular matrix to form a new blood vessel branch, stimulated by vascular endothelial growth factor (VEGF) and others. Abbreviations: pi3k,

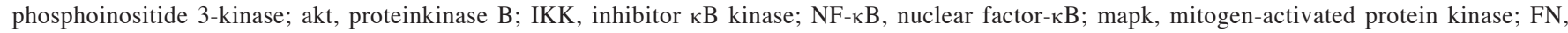
fibronectin; hTERT, human telomerase reverse transcriptase, HPV E6, Human Papilloma Virus early protein 6; SAP, saposin.

within tumor cells, including direct ceramide application in in vitro and animal studies, stimulation of ceramide de novo synthesis, sphingomyelinase activity stimulation, and inhibition of ceramide utilization $(87,88)$. In HNSCC, Gu et al showed promising anticancer effects of vitamin E succinate to inhibit HNSCC growth and viability via ceramide-mediated apoptosis. This was found in both cancer cells and in a xenograft cancer mouse model (89). Other groups have attempted to find ways to deliver ceramide into HNSCC cells successfully (90).

\section{Angiogenesis}

Tumor growth depends on a sufficient supply of oxygen and nutrition, and therefore requires an ability to induce angiogenesis (91). The current conceptual framework of molecular angiogenesis divides the process into two principal phases (92): First, structural changes of the vascular basement membrane via tumor secreted MMP and growth factors leads to a remodeled vascular basement membrane (provisional matrix). In a second phase, the actual extension of the vascular bed, there is formation of a new vascular basement membrane in response to secreted vascular endothelial growth factor (VEGF), basic fibroblast growth factor and platelet-derived growth factor.

In HNSCC, secreted VEGF has been shown to induce endothelial proliferation, which, in combination with anti- proliferative TGF- $\beta$, helps to form the anatomical space needed for angiogenesis. Its interaction with prostaglandin E2, inducing cellular locomotion, also could contribute to angiogenesis (93). EGFR directed therapy is, apart from interrupting autocrine growth signal stimulation, thought to inhibit VEGF release and thus also interferes with tumor angiogenesis (94).

There is also an extensive amount of research effort targeted directly against angiogenesis. These therapies can be divided into two major groups: The first group consists of direct VEGF antibodies (Bevacizumab) and soluble VEGF receptors (Aflibercept) which deplete VEGF and make it unavailable to promote angiogenesis. Overall, this approach has shown a benefit (95), although there is concern that diverse gene alterations affecting post-receptor signaling could blunt the response in some patients, analogous to the K-ras mutation in EGFR receptor blockers. Recently, Newman et al showed that in a HNSCC xenograft model, the response to Bevacizumab was dependent upon concomitant expression of CD147 (96). The second group of anti-angiogenic drugs targets the intracellular portion of the VEGF receptor and prevents its phosporylation (97).

\section{Escaping the immune response}

Immunotherapy for HNSCC is a very attractive treatment option of growing importance. HNSCC arise in a highly 
immune reactive environment. Their survival therefore necessitates several mechanisms to evade the immune system. These rely on avoidance of detection (e.g. by down-regulating HLA expression), induced apoptosis of surrounding T-cells, and local suppressive immune modulation (98). In addition to direct antibodies against EGFR and VEGF mentioned above, immune modulators enhancing the host immune response such as interferon $\alpha$ and interleukin- 2 could bear significant weight in treatment regimens. Another approach is the development of antibodies targeting antigens either overexpressed, or exclusively present in cancer cells. Several immune modulating agents and experimental antibodies which are summarized in Table I, are under investigation.

\section{Conclusion}

With regard to the recent cytogenetic studies multiple signaling pathways are activated in HNSCC (summarized in Fig. 1). Of the enormous amount of research done on identifying molecular pathogenesis and eventually developing therapeutic agents in HNSCC, EGFR antibodies are so far the most advanced in application. However, results using these agents have fallen below expectations. With the emerging recognition of the importance of post-EGFR signaling in predicting susceptibility to EGFR antibody treatment has illuminated some of the possible reasons for these unmet expectations. Much work remains in analyzing and understanding the molecular pathways promoting malignant behavior in HNSCC. On a positive note, there are a variety of other promising targets in multiple disease mechanisms, and knowledge about them is expanding at a rapid pace. From an overall perspective, halting invasion and metastasis formation alone could be sufficient to give rise to substantial clinical improvement, as these pathways are primarily responsible for a large proportion of morbidity and mortality in HNSCC.

\section{References}

1. Berrino F, De Angelis R, Sant M, Rosso S, Bielska-Lasota M, Coebergh JW and Santaquilani M: Survival for eight major cancers and all cancers combined for European adults diagnosed in 1995-99: results of the EUROCARE-4 study. Lancet Oncol 8: 773-783, 2007.

2. Jemal A, Siegel R, Ward E, Hao Y, Xu J, Murray T and Thun MJ: Cancer statistics 2008. CA Cancer J Clin 58: 71-96, 2008.

3. Dan S, Naito M and Tsuruo T: Selective induction of apoptosis in Philadelphia chromosome-positive chronic myelogenous leukemia cells by an inhibitor of BCR-ABL tyrosine kinase, CGP 57148. Cell Death Differ 5: 710-715, 1998.

4. Ritta M, De Andrea M, Mondini M, et al: Cell cycle and viral and immunologic profiles of head and neck squamous cell carcinoma as predictable variables of tumor progression. Head Neck 31: 318-327, 2008.

5. Quon HFF and Liu BJ: Cummings, potential molecular prognostic markers in head and neck squamous cell carcinomas. Head Neck 23: 147-159, 2001.

6. Hanahan D and Weinberg RA: The hallmarks of cancer. Cell 100: 57-70, 2000.

7. Field JK and Spandidos DA: Expression of oncogenes in human tumours with special reference to the head and neck region. J Oral Pathol 16: 97-107, 1987.

8. Spandidos DA, Liloglou T and Field JK: Prognostic significance of tumor suppressor genes in human malignancy. Stem Cells 11: 194-198, 1993.

9. Field JK: The role of oncogenes and tumor-suppressor genes in the aetiology of oral, head and neck squamous cell carcinoma. J Royal Soc Med 88: 35-39, 1995
10. Kiaris H, Spandidos DA, Jones AS and Field JK: Loss of heterozygosity and microsatellite instability of the H-ras gene in cancer of the head and neck. Int J Oncol 5: 579-582, 1994.

11. Kiaris H, Spandidos DA, Jones AS, Vaughan ED and Field JK: Mutations, exp as proto-oncogene in squamous cell carcinomas of the head and neck. Br J Cancer 72: 123-128, 1995

12. Spandidos DA, Lamothe A and Field JK: Multiple transcriptional activation of cellular oncogenes in human head and neck solid tumours. Anticancer Res 5: 221-224, 1985.

13. Field JK, Lamothe A and Spandidos DA: Clinical relevance of oncogene expression in head and neck tumours. Anticancer Res 6: 595-600, 1986

14. Field JK, Spandidos DA, Stell PM, Vaughan ED, Evan GI and Moore JP: Elevated expression of the c-myc oncoprotein correlates with poor prognosis in head and neck squamous cell carcinoma. Oncogene 4: 1463-1468, 1989.

15. Field JK, Tsiriyotis C, Zoumpourlis V, Howard P, Spandidos DA and Jones A: Allele loss on chromosome 3 in squamous cell carcinoma of the head and neck correlates with poor clinical prognostic indicators. Int J Oncol 4. 543-549, 1994.

16. Field JK, Kiaris H and Risk JM: Allelotype of squamous cell carcinoma of the head and neck: fractional allele loss correlates with survival. Br J Cancer 72: 1180-1188, 1995.

17. Nawroz H, Vanderriet P, Hruban RH, Koch W, Ruppert JM and Sidransky D: Allelotype of head and neck squamous cell carcinoma. Cancer Res 54: 1152-1155, 1994.

18. Ah-See KW, Cooke TG, Pickford IR, Soutar D and Balmain A: An allelotyp of squamous cell carcinoma of the head and neck using microsatellite markers. Cancer Res 54: 1617-1621, 1994

19. Gasco M and Crook T: The p53 network in head and neck cancer. Oral Oncol 39: 222-231, 2003.

20. Field JK, Pavelic ZP, Spandidos DA, Stambrook PJ, Jones AS and Gluckman JL: The role of the p53 tumor suppressor gene in squamous cell carcinoma of the head and neck. Arch Otolaryngol Head Neck Surg 119: 1118-1122, 1993.

21. Field JK, Malliri A, Jones AJ and Spandidos DA: Mutations in the op53 gene at coden 249 are rare in squamous cell carcinoma of the head and neck. Int J Oncol 1: 253-256, 1992.

22. Field JK, Zoumpourlis V, Spandidos DA and Jones AG: p53 expression and mutations in squamous cell carcinoma of the head and neck: expression correlates with the patients' use of tobacco and alcohol. Cancer Detect Prev 18: 197-208, 1994.

23. Field JK, Spandidos DA and Stell PM: Overexpression of p53 gene in head and neck cancer, linked with heavy smoking and drinking. Lancet 339: 502-503, 1992.

24. Vogelstein B, Lane D and Levine AJ: Surfing the p53 network. Nature 408: 307-310, 2000.

25. Shangary S and Wang S: Small-molecule inhibitors of the MDM2-p53 protein-protein interaction to reactivate $\mathrm{p} 53$ function: a novel approach for cancer therapy. Annu Rev Pharmacol Toxicol 49: 223-241, 2009.

26. Olden K and Yamada KM: Mechanism of the decrease in the major cell surface protein in chick embryo fibroblasts after transformation. Cell 11: 957-969, 1977.

27. Pannizut B, Carlevato MT and Ferro S: Adhesion molecules in squamous cell carcinoma of the larynx: possible indication of prognosis. Acta Otorhinol Ital 17: 347-356, 1997.

28. Zidar N, Gale N, Kambic V and Fischinger J: Expression of tenascin and fibronectin in benign epithelial hyperplastic lesions and squamous carcinoma of the larynx. Anticancer Res 21: 451-454, 2001

29. Ishitoya J, Toriyama M, Oguchi N, Kitamura K, Ohshima M, Asano $\mathrm{K}$ and Yamamoto T: Gene amplification and overexpression of EGF receptor in squamous cell carcinomas of the head and neck. Br J Cancer 59: 559-562, 1989.

30. Issing WJ: Detection of an 'autocrine loop' between EGF receptor and TGF-alpha in head-neck carcinomas. Laryngorhinootologie 76: 415-420, 1997.

31. Grandis JR, Chakraborty A, Zeng Q, Melhem MF and Tweardy DJ: Downmodulation of TGF-alpha protein expression with antisense oligonucleotides inhibits proliferation of head and neck squamous carcinoma but not normal mucosal epithelial cells. J Cell Biochem 69: 55-62, 1998.

32. Albanell J, Codony-Servat J, Rojo F, et al: Activated extracellular signal-regulated kinases: association with epidermal growth factor receptor/transforming growth factor alpha expression in head and neck squamous carcinoma and inhibition by anti-epidermal growth factor receptor treatments. Cancer Res 61: 6500-6510, 2001. 
33. Ang KK, Berkey BA, Tu X, et al: Impact of epidermal growth factor receptor expression on survival and pattern of relapse in patients with advanced head and neck carcinoma. Cancer Res 62: 7350-7356, 2002.

34. Burtness B: The role of cetuximab in the treatment of squamous cell cancer of the head and neck. Expert Opin Biol Ther 5: 1085-1093, 2005.

35. Bonner JA, Harari PM, Giralt J, et al: Radiotherapy plus cetuximab for squamous-cell carcinoma of the head and neck. $\mathrm{N}$ Engl J Med 354: 567-578, 2006.

36. Vermorken JB, Mesia R, Rivera F, et al: Platinum-based chemotherapy plus cetuximab in head and neck cancer. N Engl J Med 359: 1116-1127, 2008

37. Jean GW and Shah SR: Epidermal growth factor receptor monoclonal antibodies for the treatment of metastatic colorectal cancer. Pharmacotherapy 28: 742-754, 2008.

38. Vincenzi B, Santini D and Tonini G: Biological interaction between anti-epidermal growth factor receptor agent cetuximab and magnesium. Expert Opin Pharmacother 9: 1267-1269, 2008.

39. Giro C, Berger B, Bolke E, et al: High rate of severe radiation dermatitis during radiation therapy with concurrent cetuximab in head and neck cancer: results of a survey in EORTC institutes. Radiother Oncol 90: 166-171, 2009.

40. Gibson TB, Ranganathan A and Grothey A: Randomized phase III trial results of panitumumab, a fully human anti-epidermal growth factor receptor monoclonal antibody, in metastatic colorectal cancer. Clin Colorectal Cancer 6: 29-31, 2006.

41. Yang XD, Jia XC, Corvalan JR, Wang P and Davis CD: Development of ABX-EGF, a fully human anti-EGF receptor monoclonal antibody, for cancer therapy. Crit Rev Oncol Hematol 38: 17-23, 2001.

42. Martinelli E, De Palma R, Orditura M, De Vita F and Ciardiello F: Anti-epidermal growth factor receptor monoclonal antibodies in cancer therapy. Clin Exp Immunol 158: 1-9, 2009.

43. Lievre A, Bachet JB, Le Corre D, et al: KRAS mutation status is predictive of response to cetuximab therapy in colorectal cancer. Cancer Res 66: 3992-3995, 2006.

44. Squarize CH, Castilho RM, Sriuranpong V, Pinto DS and Gutkind JS: Molecular cross-talk between the NFkappaB and STAT3 signaling pathways in head and neck squamous cel carcinoma. Neoplasia 8: 733-746, 2006.

45. Wu X, Zhao H, Do KA, Johnson MM, Dong Q, Hong WK and Spitz MR: Serum levels of insulin growth factor (IGF-I) and IGFbinding protein predict risk of second primary tumors in patients with head and neck cancer. Clin Cancer Res 10: 3988-3995, 2004.

46. Slomiany MG, Black LA, Kibbey MM, Tingler MA, Day TA and Rosenzweig SA: Insulin-like growth factor-1 receptor and ligand targeting in head and neck squamous cell carcinoma. Cancer Lett 18: 269-279, 2007.

47. Gorogh T, Maune S, Lippert BM, et al: Transcriptional repression of the human fibronectin gene in laryngeal squamous cell carcinoma cells. J Cancer Res Clin Oncol 127: 166-172, 2001.

48. Sporn MB: The war on cancer. Lancet 347: 1377-1381, 1996.

49. Mattijssen V, Peters HM, Schalkwijk L, Manni JJ, van't HofGrootenboer B, de Mulder PH and Ruiter DJ: E-cadherin expression in head and neck squamous-cell carcinoma is associated with clinical outcome. Int J Cancer 55: 580-585, 1993.

50. Al Moustafa AE, Alaoui-Jamali MA, Batist G, et al: Identification of genes associated with head and neck carcinogenesis by cDNA microarray comparison between matched primary normal epithelial and squamous carcinoma cells. Oncogene 21: 2634-2640, 2002

51. Kyzas PA, Stefanou D, Batistatou A, Agnantis NJ, Nakanishi Y, Hirohashi S and Charalabopoulos K: Dysadherin expression in head and neck squamous cell carcinoma: association with lymphangiogenesis and prognostic significance. Am J Surg Pathol 30: 185-193, 2006.

52. Görögh T, Beier UH, Baumken J, Meyer JE, Hoffmann M, Gottschlich S and Maune S: Metalloproteinases and their inhibitors: influence on tumor invasiveness and metastasis formation in head and neck squamous cell carcinomas. Head Neck 28: 31-39, 2006

53. Pacheco M, Kowalski LP, Nishimoto IN and Brentani MM: Differential expression of c-jun and c-fos mRNAs in squamous cell carcinoma of the head and neck: associations with uPA, gelatinase B, and matrilysin mRNAs. Head and Neck 24: 24-32, 2002 .
54. Stetler-Stevenson W, Liotta LA and Kleiner DE: Extracellular matrix 6: role of matrix metalloproteinases in human tumor invasion and metastasis. FASEB J 7: 1434-1441, 1993.

55. Rosenthal EL and Matrisian LM: Matrix metalloproteases in head and neck cancer. Head Neck 28: 639-648, 2006.

56. Kagan HM and Trackman PC: Properties and function of lysyl oxidase. Am J Respir Cell Mol Biol 5: 206-210, 1991.

57. Kaneda A, Tsukamoto T, Takamura-Enya T, et al: Frequent hypomethylation in multiple promoter $\mathrm{CpG}$ islands is associated with global hypomethylation, but not with frequent promoter hypermethylation. Cancer Sci 95: 58-64, 2004.

58. Csiszar K, Fong SF, Ujfalusi A, Krawetz SA, Salvati EP, Mackenzie JW and Boyd CD: Somatic mutations of the lysyl oxidase gene on chromosome 5 q23.1 in colorectal tumors. Int J Cancer 97: 636-642, 2002.

59. Ren C, Yang G, Timme TL, Wheeler TM and Thompson TC: Reduced lysyl oxidase messenger RNA levels in experimental and human prostate cancer. Cancer Res 58: 1285-1290, 1998.

60. Kirschmann DA, Seftor EA, Fong SF, et al: A molecular role for lysyl oxidase in breast cancer invasion. Cancer Res 62: 4478-4483, 2002

61. Trivedy C, Warnakulasuriya KA, Hazarey VK, Tavassoli M, Sommer P and Johnson NW: The upregulation of lysyl oxidase in oral submucous fibrosis and squamous cell carcinoma. J Oral Pathol Med 28: 246-251, 1999.

62. Holtmeier C, Görögh T, Beier U, et al: Overexpression of a novel lysyl oxidase-like gene in human head and neck squamous cell carcinomas. Anticancer Res 23: 2585-2591, 2003.

63. Gorogh T, Weise JB, Holtmeier C, et al: Selective upregulation and amplification of the lysyl oxidase like-4 (LOXL4) gene in head and neck squamous cell carcinoma. J Pathol 212: 74-82, 2007.

64. Lucero A and Kagan HM: Lysyl oxidase: an oxidative enzyme and effector of cell function. Cell Mol Life Sci 63: 2304-2316, 2006.

65. Erler JT, Bennewith M, Nicolau N, et al: Lysyl oxidase is essential for hypoxia-induced metastasis. Nature 440: 1222-1226, 2006.

66. Weise B, Rudolph P, Heiser A, et al: LOXL4 is a selectively expressed candidate diagnostic antigen in head and neck cancer. Eur J Cancer 44: 1323-1331, 2008.

67. Bondareva A, Downey CM, Ayres F, Liu W, Boyd SK, Hallgrimsson B and Jirik FR: The lysyl oxidase inhibitor, betaaminopropionitrile, diminishes the metastatic colonization potential of circulating breast cancer cells. PLoS ONE 4: 5620, 2009.

68. Weise JB, Csiszar K, Gottschlich S, et al: Vaccination strategy to target lysyl oxidase-like 4 in dendritic cell based immunotherapy for head and neck cancer. Int J Oncol 32: 317-322, 2008.

69. Wang J, Xi L, Hunt JL, et al: Expression pattern of chemokine receptor 6 (CCR6) and CCR7 in squamous cell carcinoma of the head and neck identifies a novel metastatic phenotype. Cancer Res 64: 1861-1866, 2004.

70. Wright WE, Pereira-Smith OM and Shay JW: Reversible cellular senescence: implications for immortalization of normal human diploid fibroblasts. Mol Cell Biol 9: 3088-3092, 1989.

71. Mao L, El-Naggar AK, Fan YH, et al: Telomerase activity in head and neck squamous cell carcinoma and adjacent tissues. Cancer Res 56: 5600-5604, 1996.

72. Thurnher D, Knerer B, Formanek M and Kornfehl J: Nonradioactive semiquantitative testing for the expression levels of telomerase activity in head and neck squamous cell carcinomas may be indicative for biological tumour behaviour. Acta Otolaryngol 118: 423-427, 1998.

73. Lee BJ, Lee BH, Wang SG, et al: Change of the expression of human telomerase reverse transcriptase mRNA and human telomerase RNA after cisplatin and 5-fluorouracil exposure in head and neck squamous cell carcinoma cell lines. J Korean Med Sci 22: 73-78, 2007.

74. Li Y, Liu L, Andrews LG and Tollefsbol TO: Genistein depletes telomerase activity through cross-talk between genetic and epigenetic mechanisms. Int J Cancer 125: 286-296, 2009.

75. Park YP, Kim KD, Kang SH, Yoon do Y, Park JW, Kim JW and Lee HG: Human telomerase reverse transcriptase (hTERT): a target molecule for th treatment of cisplatin-resistant tumors. Korean J Lab Med 28: 430-437, 2008.

76. Rossi MJ, Sundararaj K, Koybasi S, et al: Inhibition of growth and telomerase activity by novel cationic ceramide analogs with high solubility in human head and neck squamous cell carcinoma cells. Otolaryngol Head Neck Surg 132: 55-62, 2005. 
77. Yang F, Zeng O, Yu G, Li S and Wang CY: Wnt/beta-catenin signaling inhibits death receptor-mediated apoptosis and promotes invasive growth of HNSCC. Cell Signal 18: 679-687, 2006.

78. Sniezek JC, Matheny KE, Westfall MD and Pietenpol JA: Dominant negative p63 isoform expression in head and neck squamous cell carcinoma. Laryngoscope 114: 2063-2072, 2004.

79. Chiang C, Dong G, Broker TR and Chow LT: Control of human papillomavirus type 11 origin of replication by the E2 family of transcription regulatory proteins. J Virol 66: 5224-5231, 1992.

80. Beier UH, Weise JB, Laudien M, Sauerwein H and Görögh T: Overexpression of Pim-1 in head and neck squamous cell carcinomas. Int J Oncol 30: 1381-1387, 2007.

81. Zippo A, De Robertis A, Serafini R and Oliviero S: PIM1dependent phosphorylation of histone $\mathrm{H} 3$ at serine 10 is required for MYC-dependent transcriptional activation and oncogenic transformation. Nat Cell Biol 9: 932-944, 2007.

82. Hakomori S: Tumor malignancy defined by aberrant glycosylation and sphingo (glyco)lipid metabolism. Cancer Res 56: 5309-5318, 1996.

83. Liao W, Haimovitz-Friedman A, Persaud RS, et al: Ataxia telangiectasia-mutated gene product inhibits DNA damageinduced apoptosis via ceramide synthase. J Biol Chem 275 17908-17917, 1999.

84. Gorogh T, Rudert H, Lippert BM, et al: Transcriptional repression of the human galactocerebrosidase gene in squamous cell carcinomas of the larynx. Int J Cancer 83: 750$754,1999$.

85. Beier UH and Gorogh T: Implications of galactocerebrosidase and galactosylcerebroside metabolism in cancer cells. Int J Cancer 115: 6-10, 2005.

86. Yang J, Yu Y and Sun S: Duerksen-Hughes, PJ, ceramide and other sphingolipids in cellular responses. Cell Biochem Biophys 40: 323-350, 2004

87. Reynolds C, Maurer BJ and Kolesnick RN: Ceramide synthesis and metabolism as a target for cancer therapy. Cancer Lett 206 169-180, 2004.
88. Lovat P, Di Sano F, Corazzari M, et al: Gangliosides link the acidic sphingomyelinase-mediated induction of ceramide to 12 lipoxygenase-dependent apoptosis of neuroblastoma in response to fenretinide. J Natl Cancer Inst 96: 1288-1299, 2004.

89. Gu X, Song X, Dong Y, et al: Vitamin E succinate induces ceramide-mediated apoptosis in head and neck squamous cell carcinoma in vitro and in vivo. Clin Cancer Res 14: 1840-1848, 2008.

90. Senkal CE, Ponnusamy S, Rossi MJ, et al: Potent antitumor activity of a novel cationic pyridinium-ceramide alone or in combination with gemcitabine against human head and neck squamous cell carcinomas in vitro and in vivo. J Pharmacol Exp Ther 317: 1188-1199, 2006.

91. Folkman J: Tumor angiogenesis and tissue factor. Nat Med 2: $167-168,1996$

92. Kalluri R: Basement membranes: structure, assembly and role in tumour angiogenesis. Nat Rev Cancer 3: 422-433, 2003.

93. Benefield J, Petruzzelli GJ, Fowler S, Taitz A, Kalkanis J and Young MRI: Regulation of the steps of angiogenesis by human head and neck squamous cell carcinomas. Invasion Metastasis 16: 291-301, 1996.

94. Riedel F, Gotte K, Li M, Hormann K and Grandis JR: EGFR antisense treatment of human HNSCC cell lines down-regulates VEGF expression and endothelial cell migration. Int J Oncol 21: 11-16, 2002.

95. Wagner AD, Arnold D, Grothey AA, Haerting J and Unverzagt S: Anti-angiogenic therapies for metastatic colorectal cancer. Cochrane Database Syst Rev CD005392, 2009.

96. Newman R, Helman EE, Safavy S, Zhang W and Rosenthal EL: EMMPRIN expression is required for response to bevacizumab therapy in HNSCC xenografts. Cancer Lett 274: 313-318, 2009.

97. Escudier B, Eisen T, Stadler WM, et al: Sorafenib in advanced clear-cell renal-cell carcinoma. N Engl J Med 356: 125-134, 2007.

98. Rapidis AD and Wolf GT: Immunotherapy of head and neck cancer: current and future considerations. J Oncol ID346345, 2009. 